\title{
Gravimetrically prepared carbon dioxide standards in support of atmospheric research
}

\author{
Bradley D. Hall ${ }^{1}$, Andrew M. Crotwell ${ }^{1,2}$, Benjamin R. Miller ${ }^{1,2}$, Michael Schibig ${ }^{3}$, and James W. Elkins ${ }^{1}$ \\ ${ }^{1}$ Global Monitoring Division, National Oceanic and Atmospheric Administration, \\ 325 Broadway, Boulder, Colorado 80305, USA \\ ${ }^{2}$ Cooperative Institute for Research in Environmental Science, University of Colorado, Boulder, Colorado 80309, USA \\ ${ }^{3}$ Climate and Environmental Physics, Physics Institute and Oeschger Centre for Climate Change Research, \\ University of Bern, Bern, Switzerland
}

Correspondence: Bradley D. Hall (bradley.hall@noaa.gov)

Received: 20 August 2018 - Discussion started: 3 September 2018

Revised: 11 December 2018 - Accepted: 21 December 2018 - Published: 28 January 2019

\begin{abstract}
We have explored a one-step method for gravimetric preparation of $\mathrm{CO}_{2}$-in-air standards in aluminum cylinders. We consider both adsorption to stainless steel surfaces used in the transfer of highly pure $\mathrm{CO}_{2}$ and adsorption of $\mathrm{CO}_{2}$ to cylinder walls. We demonstrate that $\mathrm{CO}_{2}$-inair standards can be prepared with relatively low uncertainty ( $\sim 0.04 \%, \sim 95 \%$ confidence level) by introducing aliquots whose masses are known to high precision and by using wellcharacterized cylinders. Five gravimetric standards, prepared over the nominal range of 350 to $490 \mu \mathrm{mol} \mathrm{mol}^{-1}$ (parts per million, ppm), showed excellent internal consistency, with residuals from a linear fit equal to $0.05 \mathrm{ppm}$. This work compliments efforts to maintain the World Meteorological Organization, Global Atmosphere Watch, mole fraction scale for carbon dioxide in air, widely used for atmospheric monitoring. This gravimetric technique could be extended to other atmospheric trace gases, depending on the vapor pressure of the gas.
\end{abstract}

\section{Introduction}

Numerous laboratories make routine measurements of atmospheric carbon dioxide to better understand its sources, sinks, and temporal variability. These measurements are typically calibrated using high-pressure gas standards containing $\mathrm{CO}_{2}$ in air (typically natural air with assigned $\mathrm{CO}_{2}$ mole fractions), traceable to primary standards prepared or analyzed using absolute methods, such as manometry (Keeling et al.,
1986; Zhao and Tans, 2006) and gravimetry (Machida et al., 2011; Rhoderick et al., 2016; Brewer et al., 2014), which provide traceability to the International System of Units (SI). The World Meteorological Organization (WMO) Global Atmosphere Watch (GAW) initially adopted the Scripps Institution of Oceanography scale (Keeling et al., 1986) and subsequently the National Oceanic and Atmospheric Administration (NOAA) scale (Zhao et al., 1997), both of which are based on repeated manometric measurements of a suite of primary standards, for WMO-affiliated monitoring networks. The WMO scale has been updated over the years as understanding has improved and measurement records of primary standards have increased (Keeling et al., 2002, 1986; Zhao and Tans, 2006).

Determining the absolute amount of $\mathrm{CO}_{2}$ in air is a challenge for both gravimetric and manometric methods, particularly since the relative uncertainties must be very small $(\sim 0.006 \% 1 \sigma$, or about a factor of 4 lower than the WMO network compatibility goal of $0.1 \mathrm{ppm}-\mathrm{WMO}, 2018$ ) in order to assess changes (drift) in cylinders over many years. Long-term monitoring of atmospheric $\mathrm{CO}_{2}$ requires a stable reference, sufficient to identify small atmospheric gradients (of the order of $0.1 \mu \mathrm{molmol}{ }^{-1}$, or $0.1 \mathrm{ppm}$, in the remote troposphere). Hereafter we will use parts per million for micromoles per mole. Both methods can be influenced by the adsorption of $\mathrm{CO}_{2}$ to surfaces. There is increasing evidence that $\mathrm{CO}_{2}$ can adsorb to the internal surfaces of cylinders and desorb with decreasing pressure (Langenfelds et al., 2005; Miller et al., 2015; Leuenberger et al., 2015; Brewer et al., 
2018; Schibig et al., 2018). This impacts both the gravimetrically assigned mole fraction and the mole fraction of $\mathrm{CO}_{2}$ in air withdrawn from cylinders over time. Further, since cylinder characteristics may differ among cylinder manufacturers, understanding the behavior of $\mathrm{CO}_{2}$ in cylinders is critical to maintaining stable scales over time.

The gravimetric technique can employ multiple steps, in which the target gas $\left(\mathrm{CO}_{2}\right.$ in this case) is diluted to the desired amount fraction. For example, Brewer et al. (2014) first prepared standards with mole fractions of a few percent, then made dilutions of those to the range needed for ambient monitoring ( $\sim 400 \mathrm{ppm})$. Others have opted to dilute $\mathrm{CO}_{2}$ to part per million levels in one step (Machida et al., 2011). Matrix gases can also be added in different ways: $\mathrm{CO}_{2}$ can be mixed with individual gases $\left(\mathrm{N}_{2}, \mathrm{O}_{2}, \mathrm{Ar}\right)$ to form an air-like matrix, or $\mathrm{CO}_{2}$ can be added to natural air from which the $\mathrm{CO}_{2}$ has been removed. Methods of targeting stable isotopes of $\mathrm{CO}_{2}$ (e.g., ${ }^{13} \mathrm{C}-\mathrm{CO}_{2}$ ) to better match natural abundances have also been explored (Brewer et al., 2014).

Here we describe one-step preparation of $\mathrm{CO}_{2}$-in-air compressed gas standards in aluminum cylinders. We used information gained from recent decanting experiments (Schibig et al., 2018) to correct for $\mathrm{CO}_{2}$ adsorption to the cylinder walls. This work was undertaken to support NOAA manometric efforts and learn more about the behavior of $\mathrm{CO}_{2}$ in aluminum cylinders.

\section{Experimental methods}

Standards were prepared in $29.5 \mathrm{~L}$ Luxfer aluminum cylinders ( $22 \mathrm{~kg}$ empty) (Scott Marrin, Inc., Riverside, CA), with brass packless valves (Ceodeux). We chose these cylinders for two reasons. First, we wanted to perform the dilutions in one step and therefore needed relatively large cylinders. Second, we wanted to use cylinders that were well characterized. We have considerable experience with $\mathrm{CO}_{2}$ in air in this type of cylinder. Specific to this work, all cylinders used were filled with natural air and decanted several times for $\mathrm{CO}_{2}$ adsorption studies (Schibig et al., 2018) prior to being used for gravimetric standards described here.

For this gravimetric work, each cylinder was evacuated to $\sim 30$ mtorr (4 Pa) and weighed on a mass comparator (Sartorius CCE40K3: $40 \mathrm{~kg}$ capacity, $2 \mathrm{mg}$ readability) relative to a control cylinder of similar mass and volume. The mass comparator was calibrated using a $10 \mathrm{~kg}$ mass (Troemner), and linearity over the working range was confirmed by adding a $5 \mathrm{~kg}$ mass (Mettler Toledo) to the reference cylinder. We then added $\sim 50 \mathrm{psi}(0.34 \mathrm{MPa})$ natural air containing 402 or $408 \mathrm{ppm} \mathrm{CO} 2$ determined by analysis (WMO X2007 scale). Cylinders were then vented, partially evacuated to $\sim 400$ torr $(53 \mathrm{kPa})$, and weighed. The mass of residual air along with the mole fraction of $\mathrm{CO}_{2}$ was used to calculate the initial mass of $\mathrm{CO}_{2}$ in the cylinder. We did not evacuate the cylinders further because $\mathrm{CO}_{2}$ adsorption studies (Schibig et al., 2018) were performed at pressures ranging from 0.1 to 13.8 MPa. The Schibig et al. (2018) work provided a means to determine the amount of $\mathrm{CO}_{2}$ adsorbed to cylinder walls, and we wanted to perform the gravimetric addition with a small amount of residual $\mathrm{CO}_{2}$ in the cylinders, consistent with that work. For the standards presented here, the initial $\mathrm{CO}_{2}$ in the cylinder corresponds to $<0.8 \%$ of the total $\mathrm{CO}_{2}$, and so the uncertainty associated with the mole fraction of initial $\mathrm{CO}_{2}$, derived from an independent $\mathrm{CO}_{2}$ calibration (Zhao and Tans, 2006), makes a negligible contribution to the total uncertainty (Table 1). The majority of the uncertainty in the mass of $\mathrm{CO}_{2}$ originally in the cylinder results from uncertainty in the mass determination of the residual air. Nevertheless, we include a standard uncertainty of $0.025 \%$ on the WMO X2007 $\mathrm{CO}_{2}$ scale (https:// www.esrl.noaa.gov/gmd/ccl/ccl_uncertainties_co2.html, last access: August 2018).

An initial aliquot of high-purity $\mathrm{CO}_{2}$ was added to an evacuated $50 \mathrm{~mL}$ stainless steel container with a single metal bellows valve (Swagelok, model SS-4H) (pressure rated to $1000 \mathrm{psi}$, or $6.90 \mathrm{MPa}$, at $37^{\circ} \mathrm{C}$ ). After $\mathrm{CO}_{2}$ was loaded into the $50 \mathrm{~mL}$ container at the desired pressure, it was cryogenically transferred to a $5 \mathrm{~mL}$ stainless steel container, also with a metal bellows valve (total mass $\sim 150 \mathrm{~g}$ ) that had been evacuated and weighed previously. The $\mathrm{CO}_{2}$ was cryogenically purified by freezing at $-197^{\circ} \mathrm{C}$ and pumping off non-condensible gases. We estimate the purity of the $\mathrm{CO}_{2}$ source at $99.994 \%$ and that of the cryogenically purified $\mathrm{CO}_{2}$ aliquots at $99.997 \pm 0.002 \%$ (Table 2). In this smaller volume, both liquid and vapor phases of $\mathrm{CO}_{2}$ would be present at room temperature $\left(18^{\circ} \mathrm{C}\right.$ in this case). Note that the vapor pressure of $\mathrm{CO}_{2}$ at $18^{\circ} \mathrm{C}$ is $\sim 795 \mathrm{psi}(5.48 \mathrm{MPa})$ and that our $5 \mathrm{~mL}$ container and valve was rated to $1000 \mathrm{psi}(6.89 \mathrm{MPa})$. We employed this secondary transfer to a smaller container so that we could weigh $\sim 1.5 \mathrm{~g}$ of $\mathrm{CO}_{2}$ on a balance with $0.01 \mathrm{mg}$ readability (Mettler Toledo AT201, $200 \mathrm{~g}$ capacity). The $50 \mathrm{~mL}$ container used in the first step is too large to be weighed on the AT-201. This is an important aspect of this work. Without this secondary step, our uncertainties would have been about a factor of 10 larger. The mass of $\mathrm{CO}_{2}$ in each $5 \mathrm{~mL}$ aliquot was determined by weighing the $5 \mathrm{~mL}$ container relative to a control object of similar mass and density (sequence ABABA...). The AT-201 was calibrated using internal weights and span-checked by adding a $2.0000 \mathrm{~g}$ mass to the $5 \mathrm{~mL}$ container.

Each purified $\mathrm{CO}_{2}$ aliquot was transferred from the $5 \mathrm{~mL}$ container to a partially evacuated cylinder on a stainless steel vacuum manifold using a pressurization-expansion method (Fig. 1) (Dlugokencky et al., 2005). The cylinder was connected to the vacuum manifold using a 1/8 in. o.d. AT-steel transfer line. AT steel, also known as "activity tested steel" (Grace Discovery Science, Columbia, MD), is treated using vapor deposition to improve surface inertness. In initial tests we found that AT steel performed better than other types of stainless steel, but in subsequent tests both $1 / 8$ in. o.d. stain- 
Table 1. Components and standard uncertainties associated with standard preparation.

\begin{tabular}{|c|c|c|c|c|c|c|c|c|}
\hline \multirow[b]{2}{*}{ Cylinder } & \multicolumn{7}{|c|}{ Components } & \multirow[b]{2}{*}{$\begin{array}{r}\mu \_n_{\mathrm{CO}_{2}} \\
\mathrm{~mol}\end{array}$} \\
\hline & $\begin{array}{r}\mathrm{CO}_{2 \_\mathrm{a}} \\
\mathrm{g}\end{array}$ & $\mu_{-} \mathrm{CO}_{2 \_}{ }_{\mathrm{g}}^{\mathrm{a}}$ & $\begin{array}{r}\mathrm{CO}_{2 \_} \mathrm{b} \\
\mathrm{g}\end{array}$ & $\begin{array}{r}\mu \_\mathrm{CO}_{2} \_\mathrm{b} \\
\mathrm{g}\end{array}$ & $\begin{array}{r}\text { Air } \\
\mathrm{g}\end{array}$ & $\mu \quad \begin{array}{r}\text { Air } \\
\mathrm{g}\end{array}$ & $\begin{array}{r}n_{\mathrm{CO}_{2}} \\
\mathrm{~mol}\end{array}$ & \\
\hline CB11873 & 1.36062 & 0.00008 & $6.80 \times 10^{-3}$ & $2.24 \times 10^{-5}$ & 2515.630 & 0.033 & $3.1070 \times 10^{-2}$ & $1.1888 \times 10^{-6}$ \\
\hline CB11906 & 1.52917 & 0.00007 & $7.28 \times 10^{-3}$ & $1.25 \times 10^{-5}$ & 2542.391 & 0.026 & $3.4911 \times 10^{-2}$ & $1.3934 \times 10^{-6}$ \\
\hline CB11941 & 1.51156 & 0.00015 & $1.07 \times 10^{-2}$ & $1.25 \times 10^{-5}$ & 2470.254 & 0.030 & $3.4589 \times 10^{-2}$ & $3.4205 \times 10^{-6}$ \\
\hline CB11976 & 1.66307 & 0.00011 & $7.32 \times 10^{-3}$ & $1.18 \times 10^{-5}$ & 2445.190 & 0.014 & $3.7954 \times 10^{-2}$ & $2.5140 \times 10^{-6}$ \\
\hline \multirow[t]{2}{*}{ CB12009 } & 1.71751 & 0.00007 & $7.72 \times 10^{-3}$ & $1.81 \times 10^{-5}$ & 2307.297 & 0.039 & $3.9200 \times 10^{-2}$ & $1.6437 \times 10^{-6}$ \\
\hline & & & \multicolumn{4}{|c|}{ Adjustments } & Amount fraction & \\
\hline Cylinder & $\begin{array}{l}n_{\text {air }} \\
\text { mol }\end{array}$ & $\begin{array}{r}\mu \_n_{\text {air }} \\
\text { mol }\end{array}$ & $\begin{array}{r}X_{\mathrm{CO}_{2}, \mathrm{ad}} \\
\text { ppm }\end{array}$ & $\begin{array}{r}\mu_{-} X_{\mathrm{CO}_{2}, \mathrm{ad}} \\
\mathrm{ppm}\end{array}$ & $\begin{array}{r}X_{\mathrm{CO}_{2}, \mathrm{dil}} \\
\text { ppm }\end{array}$ & $\mu_{-} X_{\mathrm{CO}_{2}, \mathrm{dil}}$ & $\begin{array}{r}X_{\mathrm{CO}_{2}} \\
\text { ppm }\end{array}$ & $\begin{array}{r}\mu_{-} X_{\mathrm{CO}_{2}} \\
\text { ppm }\end{array}$ \\
\hline CB11873 & 86.8651 & 0.0144 & -0.015 & 0.01 & 0.01 & 0.01 & 357.545 & 0.059 \\
\hline CB11906 & 87.7891 & 0.0146 & -0.015 & 0.01 & 0.01 & 0.01 & 397.497 & 0.062 \\
\hline CB11941 & 85.2982 & 0.0142 & -0.017 & 0.01 & 0.01 & 0.01 & 405.337 & 0.073 \\
\hline CB11976 & 84.4328 & 0.0140 & -0.020 & 0.01 & 0.01 & 0.01 & 449.301 & 0.075 \\
\hline CB12009 & 79.6713 & 0.0133 & -0.022 & 0.01 & 0.01 & 0.01 & 491.763 & 0.077 \\
\hline
\end{tabular}

Note: Entries preceded by “ $\mu_{-}$" represent standard uncertainties $(\sim 68 \%$ confidence level $)$.

$\mathrm{CO}_{2}$ a: mass of $\mathrm{CO}_{2}$ aliquot in a $5 \mathrm{~mL}$ container, added to cylinder.

$\mathrm{CO}_{2} \_$b: initial mass of $\mathrm{CO}_{2}$ in the cylinder (based on analyzed mole fraction and mass of residual air).

Air: mass of air (includes $10-15 \mathrm{~g}$ residual air initially present in cylinder).

$n_{\mathrm{CO}_{2}}$ : total amount of $\mathrm{CO}_{2}$ (moles) (0.99997 purity correction applied).

$n_{\text {air }}:$ total amount of air (moles).

$X_{\mathrm{CO}_{2} \text {, ad }}$ : correction applied to account for adsorption to cylinder walls.

$X_{\mathrm{CO}_{2} \text {, dil }}$ : correction applied to account for $\mathrm{CO}_{2}$ in the dilution gas.

$X_{\mathrm{CO}_{2}}$ : mole fraction of $\mathrm{CO}_{2}$.

Table 2. $\mathrm{CO}_{2}$ purity assessment.

\begin{tabular}{lrl}
\hline Component & Fraction & Method \\
\hline $\mathrm{CO}_{2}$ (source) $_{\mathrm{CO}_{2} \text { (aliquot) }^{\mathrm{a}}}$ & 0.99994 & \\
$\mathrm{H}_{2} \mathrm{O}$ & 0.99997 & \\
$\mathrm{CH}_{4}$ & 0.00003 & electrolytic \\
$\mathrm{CO}$ & 0.00002 & laser spectroscopy \\
$\mathrm{N}_{2} \mathrm{O}$ & 0.00001 & laser spectroscopy \\
Ethyne & $2 \times 10^{-8}$ & GC-ECD $^{\mathrm{b}}$ \\
Ethene & $3 \times 10^{-9}$ & GC-GCMS $^{\mathrm{c}}$ \\
Propane & $2 \times 10^{-9}$ & GC-GCMS \\
Other hydrocarbons & $2 \times 10^{-9}$ & GC-GCMS \\
Total non-condensible & 0.00002 & residual pressure \\
\hline
\end{tabular}

a Since the $\mathrm{CO}_{2}$ aliquots were cryogenically purified to remove

non-condensible gases, we calculate the aliquot purity based on $\mathrm{H}_{2} \mathrm{O}$ only.

Non-condensibles include $\mathrm{N}_{2}, \mathrm{O}_{2}, \mathrm{Ar}, \mathrm{H}_{2}, \mathrm{CO}$, and $\mathrm{CH}_{4}$.

${ }^{\mathrm{b}}$ Gas Chromatography with Electron Capture Detection

c Gas Chromatography with Mass Selective Detection

less steel and 1/8 in. o.d. AT steel performed similarly (see Sect. 3).

To transfer the aliquot to the cylinder, the manifold and transfer lines were preheated to $\sim 60^{\circ} \mathrm{C}$ and evacuated to 5 mtorr $(0.7 \mathrm{~Pa})$. In quick succession, the cylinder valve was opened and the valve on the $5 \mathrm{~mL}$ container was opened, allowing $\mathrm{CO}_{2}$ to expand into the cylinder. The expansion of

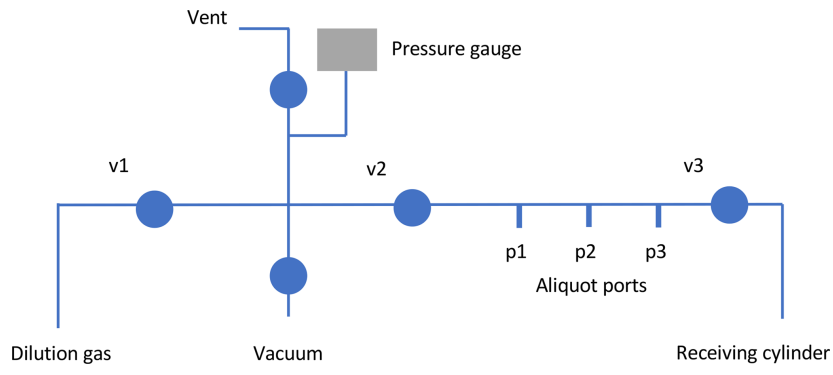

Figure 1. Schematic of the blending manifold. The sample aliquot $(5 \mathrm{~mL})$ was connected to one of three aliquot inlet ports (p1, p2, p3). The sample was transferred to the receiving cylinder by opening the cylinder valve (with v2 closed), opening the valve on the $5 \mathrm{~mL}$ vessel, and then alternately pressurizing the section between valves $\mathrm{v} 2$ and v3 and opening v3 to send the gas to the cylinder. The sample manifold is constructed of $1 / 4$ in. o.d. stainless steel tubing with welded or Swagelok VCR connections. Valves are stainless steel, diaphragm-sealed (Swagelok model DSV51).

$\mathrm{CO}_{2}$ resulted in significant cooling of the $5 \mathrm{~mL}$ container, so we heated the $5 \mathrm{~mL}$ container, manifold, and transfer lines to $\sim 60^{\circ} \mathrm{C}$ while alternately pressurizing the $5 \mathrm{~mL}$ container to $\sim 200 \mathrm{psi}\left(1.38 \mathrm{MPa}\right.$ ) with $\mathrm{CO}_{2}$-free air (dilution gas) and expanding into the cylinder. After about 20 pressurizationexpansion cycles, the valve on the $5 \mathrm{~mL}$ container was closed and the cylinder pressurized with dilution gas. The $5 \mathrm{~mL}$ con- 
tainer was removed from the manifold at a cylinder pressure of $\sim 500 \mathrm{psi}(3.45 \mathrm{MPa})$, and the cylinder was then further pressurized to $1000 \mathrm{psi}(6.90 \mathrm{MPa})$ with dilution gas. Dilution gas consisted of scrubbed natural air (cryogenic ultrapure grade, Scott Marrin, Inc.; now Praxair, Los Angeles, $\mathrm{CA})$. This gas was analyzed for $\mathrm{CO}_{2}$ by nondispersive infrared analysis (NDIR; LI-COR Li-7000). Samples of dilution gas were compared to a reference of dry nitrogen $(99.999 \%)$ scrubbed using Ascarite II (Sigma Aldrich). All cylinders of dilution gas contained $0.01 \pm 0.01 \mathrm{ppm} \mathrm{CO}_{2}$. After cylinders cooled to room temperature, they were weighed on the mass comparator relative to the control cylinder.

The mole fraction of $\mathrm{CO}_{2}, X_{\mathrm{CO}_{2}}$, was calculated using Eq. (1), where $n_{\mathrm{a}}$ is the moles of $\mathrm{CO}_{2}$ transferred from the $5 \mathrm{~mL}$ container, $n_{\mathrm{b}}$ is the moles of $\mathrm{CO}_{2}$ initially present in the cylinder, $n_{\text {air }}$ is the total moles of air (sum of natural air initially present and dilution air), $p$ is the purity coefficient, $f$ is the transfer efficiency, $X_{\mathrm{CO}_{2} \text {, ad }}$ is a correction for the amount of $\mathrm{CO}_{2}$ adsorbed to the cylinder walls $\left(X_{\mathrm{CO}_{2} \text {,ad }}<0\right)$ expressed in parts per million, and $X_{\mathrm{CO}_{2} \text {, dil }}$ is the amount of $\mathrm{CO}_{2}$ in the dilution air, also expressed in parts per million.

$X_{\mathrm{CO}_{2}}=\frac{p f n_{\mathrm{a}}+n_{\mathrm{b}}}{p f n_{\mathrm{a}}+n_{\mathrm{b}}+n_{\mathrm{air}}}+X_{\mathrm{CO}_{2}, \mathrm{ad}}+X_{\mathrm{CO}_{2}, \text { dil }}$

The amount of each component was determined from the mass and molecular weight. For $\mathrm{CO}_{2}$ we used a molecular weight of $44.0096 \pm 0.0006 \mathrm{~g} \mathrm{~mol}^{-1}$ (consistent with a ${ }^{13} \mathrm{C}_{-} \mathrm{CO}_{2}$ content of $-29 \%$ on the Vienna Peedee belemnite (VPBD) scale, determined using off-axis integrated cavity output spectroscopy (Los Gatos Research) traceable to the University of Colorado (INSTAAR) Stable Isotope Laboratory realization of VPDB; Trolier et al., 1996; Tans et al., 2017). For the dilution gas, we used a molecular weight of $28.9602 \pm 0.0042 \mathrm{~g} \mathrm{~mol}^{-1}$. The oxygen content of the dilution gas was measured using a paramagnetic method (Beckman, E2) traceable to NIST SRM 2659A $(20.863 \pm 0.011 \%$ $\mathrm{O}_{2}$ in $\mathrm{N}_{2}$ ). Argon was taken as $0.933 \%$ (Sutour et al., 2007), and the noble gases $\mathrm{Xe}, \mathrm{Ne}$, and $\mathrm{Kr}$ were taken as 0.09, 18.0, and $1.14 \mathrm{ppm}$, respectively. Nitrogen was assumed to comprise the remaining fraction. We assumed $100 \%$ transfer efficiency ( $f=1.0$ ) with an uncertainty of $0.01 \%$ (rectangular distribution) (see Sect. 3).

The mole fraction correction for $\mathrm{CO}_{2}$ adsorbed to the cylinder walls $\left(X_{\mathrm{CO}_{2}, \text { ad }}\right)$ was determined from multiple decanting experiments (Schibig et al., 2018). Briefly, in those experiments, cylinders were filled with dry natural air $(\sim 400 \mathrm{ppm})$ and drained at $0.3 \mathrm{~L} \mathrm{~min}^{-1}$ and analyzed continuously for $\mathrm{CO}_{2}$ by NDIR. These studies showed remarkably consistent results: that the mole fraction of $\mathrm{CO}_{2}$ exiting the cylinder increased as the cylinder pressure decreased and that the data can be described with a Langmuir isotherm (Fig. 2). By fitting the data with a Langmuir isotherm as derived by Leuenberger et al. (2015), and integrating the area between the Langmuir fit and the initial $X_{\mathrm{CO}_{2}}$, we determined the amount of $\mathrm{CO}_{2}$ that desorbs from the walls as the cylin-

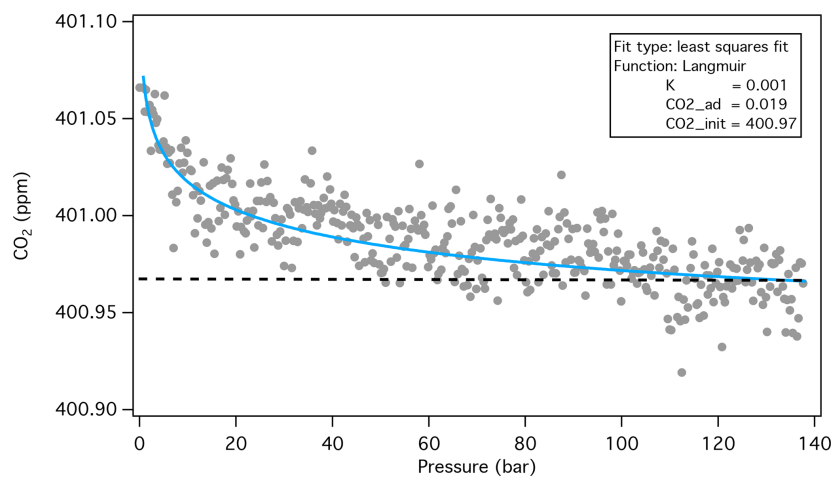

Figure 2. Typical result from Schibig et al. (2018) $\mathrm{CO}_{2}$ decanting experiments showing an increase in $X_{\mathrm{CO}_{2}}$ with decreasing cylinder pressure. The fraction of $\mathrm{CO}_{2}$ adsorbed was found by comparing the area under the Langmuir isotherm (blue line) with the area under the Langmuir isotherm but above the initial $\mathrm{CO}_{2}$ mole fraction (dashed line). The adsorbed $\mathrm{CO}_{2}$ calculated this way, expressed as a mole fraction, is similar to the parameter $\mathrm{CO}_{2}$,ad from the Langmuir model (Leuenberger et al., 2015; Schibig et al., 2018). Fit parameters, $K, \mathrm{CO}_{2} \_$ad, and $\mathrm{CO}_{2}$ init, are described in Leuenberger et al. (2015).

Table 3. Summary of $\mathrm{CO}_{2}$ adsorption experiments. For each cylinder, the test was repeated $N$ times. Adsorbed $\mathrm{CO}_{2}$ is expressed as a fraction of the total $\mathrm{CO}_{2}$ in the cylinder.

\begin{tabular}{lrrr}
\hline Cylinder & $N$ & $\begin{array}{r}\text { Average } \\
\%\end{array}$ & $\begin{array}{r}\text { SD } \\
\%\end{array}$ \\
\hline $\mathrm{CB} 11873$ & 5 & $0.0043 \%$ & $0.0003 \%$ \\
$\mathrm{CB} 11941$ & 4 & $0.0042 \%$ & $0.0003 \%$ \\
$\mathrm{CB} 11906$ & 5 & $0.0038 \%$ & $0.0004 \%$ \\
$\mathrm{CB} 11976$ & 5 & $0.0044 \%$ & $0.0005 \%$ \\
$\mathrm{CB} 12009$ & 5 & $0.0044 \%$ & $0.0002 \%$ \\
\hline
\end{tabular}

der is vented slowly to near-ambient pressure (Fig. 2). The amount of $\mathrm{CO}_{2}$ adsorbed to the walls, expressed as a fraction of the total amount of $\mathrm{CO}_{2}$ in the cylinder, was typically about $0.004 \%$ (Table 3). Although the low-flow data show very good reproducibility (Table 3 ), we assumed a standard uncertainty of $0.01 \mathrm{ppm}$.

Five standards were prepared gravimetrically, with $\mathrm{CO}_{2}$ mole fractions ranging from 357 to $492 \mathrm{ppm}$. Preparation uncertainties were determined by propagating uncertainties associated with variables in Eq. (1) (Table 1), using software available from the National Institute of Standards and Technology (NIST) (https://www.nist.gov/ programs-projects/metrology-software-project, last access: May 2014). The two most important factors influencing uncertainty are repeatability associated with weighing the purified $\mathrm{CO}_{2}$ aliquot (contributing $\sim 25 \%$ ) and the molecular weight of air (contributing $\sim 65 \%$ ). For $\mathrm{MW}_{\text {air }}$, the uncertainty is partially limited by our ability to measure $\mathrm{O}_{2}$ and calibrate the $\mathrm{O}_{2}$ analyzer. 


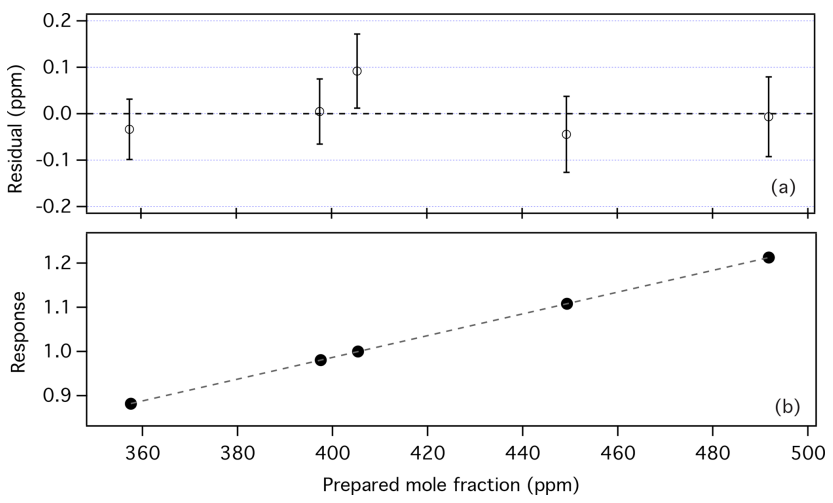

Figure 3. Normalized response of gravimetrically prepared standards, analyzed by laser spectroscopy (b). Residuals from linear fit are shown in (a), along with preparation uncertainties ( $\sim 68 \%$ confidence level, or coverage factor $k=1$ ).

\section{Results and discussion}

Following preparation, standards were analyzed using laser spectroscopy (Tans et al., 2017). Each standard was analyzed twice over a period of 2 weeks. The response was expressed as the mole fraction of $\mathrm{CO}_{2}$, calculated on the WMO X2007 $\mathrm{CO}_{2}$ scale, relative to that of $\mathrm{CB} 11941$. We use this relative response because mole fraction assignments on the X2007 scale account for differences in the abundances of stable isotopes of $\mathrm{CO}_{2}$ (mainly ${ }^{13} \mathrm{C}-\mathrm{CO}_{2}$ ) between the gravimetric standards and secondary standards used for calibration (Tans et al., 2017). For comparison, we also calculated the response based on the analyzer signal derived from a single $\mathrm{CO}_{2}$ isotopologue $\left({ }^{16} \mathrm{O}-{ }^{12} \mathrm{C}-{ }^{16} \mathrm{O}, 626\right)$. Both methods give similar results with respect to consistency of the standard set.

Table 4 and Fig. 3 show the best-fit results and residuals (difference between best fit and prepared mole fraction). All standards agree (within expanded uncertainties) with the regression line. The standard deviation of residuals is $0.05 \mathrm{ppm}$ and the largest residual is $0.09 \mathrm{ppm}$. Since the uncertainty associated with the molecular weight of air is the largest contributor to the total uncertainty, but is common to all standards, it is worth recalculating uncertainty without this contribution in order to assess consistency. Without $\mu \_\mathrm{MW}_{\text {air }}$, standard uncertainties for each standard are $40 \%-60 \%$ lower than when $\mu \_\mathrm{MW}_{\text {air }}$ is included. Recalculating the regression using these lower uncertainties, we find that the residuals do not change appreciably. However, the residual for cylinder CB11941 becomes $0.098 \mathrm{ppm}$. With a standard uncertainty of $0.046 \mathrm{ppm}, \mathrm{CB} 11941$ is not consistent with the rest of the standards. This may be the result of preparation. Cylinder CB11941 was the first standard prepared and followed testing that involved injecting high concentrations of $\mathrm{CO}_{2}$ into the manifold and transfer lines. It is possible that some residual $\mathrm{CO}_{2}$ remained in the manifold and transfer lines and was introduced into CB11941 when the manifold and transfer lines were heated. The other stan-

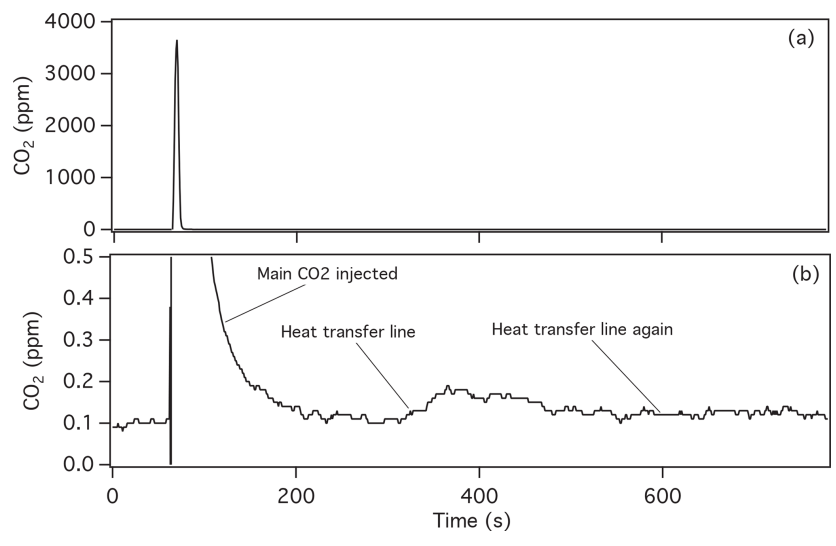

Figure 4. Measure of $\mathrm{CO}_{2}$ passing through a $\sim 1 \mathrm{~m}$ AT-steel transfer line. The peak in (a) results from $0.6 \mathrm{~cm}^{3}$ air containing $10 \%$ $\mathrm{CO}_{2}$ injected into $\mathrm{CO}_{2}$-free air flowing at $0.2 \mathrm{~L} \mathrm{~min}^{-1}$. Panel (b) is an expanded view of (a), showing a second peak at $\sim 400 \mathrm{~s}$, which results from $\mathrm{CO}_{2}$ driven off the tubing by heating.

dards were prepared following several heating cycles and are less likely to be influenced by any residual $\mathrm{CO}_{2}$.

To support our assumption of $100 \%$ transfer efficiency, we examined both the potential for adsorption of $\mathrm{CO}_{2}$ in the manifold and transfer lines and the efficiency of transferring $\mathrm{CO}_{2}$ from the $5 \mathrm{~mL}$ container to a cylinder. We tested the transfer line by flowing air containing $\sim 0.1 \mathrm{ppm} \mathrm{CO}_{2}$ at $0.2 \mathrm{~L} \mathrm{~min}^{-1}$ through $1 / 8 \mathrm{in}$. AT-steel tubing to an NDIR analyzer. Then we injected $0.6 \mathrm{~mL}$ of $10 \% \mathrm{CO}_{2}$ in air into this air stream. After the initial slug of $\mathrm{CO}_{2}$ was observed and the NDIR signal returned to baseline, we heated the transfer line and measured the additional $\mathrm{CO}_{2}$ coming off (Fig. 4). Comparing the area of the $\mathrm{CO}_{2}$ released upon heating with that of the main sample injected, we found that our AT-steel transfer line (length $1 \mathrm{~m}$ ) retained about $0.04 \%$ of $\mathrm{CO}_{2}$ in the sample. We were able to drive off most of this $\mathrm{CO}_{2}$ on the first heating cycle, with $<0.01 \%$ released on subsequent heating. Tests with stainless steel (not AT steel) showed similar results. By heating the lines multiple times and passing a large amount of $\mathrm{CO}_{2}$-free air through them, it is unlikely that a significant amount of $\mathrm{CO}_{2}$ would remain in the manifold or transfer line.

We tested the transfer efficiency from the $5 \mathrm{~mL}$ container by cryogenically moving aliquots of $\mathrm{CO}_{2}$ from one $5 \mathrm{~mL}$ container to another on a vacuum line (using liquid $\mathrm{N}_{2}$ ), without additional flushing, and measuring changes in mass. When both the initial $5 \mathrm{~mL}$ container and transfer line were heated, a transfer efficiency of $99.9 \pm 0.1 \%$ was achieved. Without heating, the same test revealed only $99 \%$ efficiency. We expect that repeated pressurization-expansion with $\mathrm{CO}_{2}-$ free air, in addition to heating, would improve the transfer efficiency of the $\mathrm{CO}_{2}$ aliquot to near $100 \%$. The relatively good agreement among the four standards prepared after CB11941 supports this assumption. It seems unlikely that 
Table 4. Analysis of $\mathrm{CO}_{2}$-in-air standards. Best-fit values were determined from a linear fit (response vs. prepared $\mathrm{CO}_{2}$ ) using orthogonal distance regression, with fit coefficients equal to $2.4644 \times 10^{-3}$ and $8.7851 \times 10^{-4}$. Uncertainties (unc.) are shown as a $\sim 68 \%$ confidence level. Results are not sensitive to how the response was normalized.

\begin{tabular}{rrrrrrr}
\hline Cylinder & $\begin{array}{r}\text { Prepared } \\
\text { ppm }\end{array}$ & $\begin{array}{r}\text { Unc. } \\
\text { ppm }\end{array}$ & Response & Unc. & $\begin{array}{r}\text { Best-fit } \\
\text { ppm }\end{array}$ & $\begin{array}{r}\text { Residual } \\
\text { ppm }\end{array}$ \\
\hline CB11873 & 357.545 & 0.059 & 0.881915 & 0.000028 & 357.512 & -0.033 \\
CB11906 & 397.497 & 0.062 & 0.980465 & 0.000025 & 397.502 & 0.005 \\
CB11941 & 405.337 & 0.073 & 1.000000 & 0.000025 & 405.429 & 0.092 \\
CB11976 & 449.301 & 0.075 & 1.108007 & 0.000025 & 449.257 & -0.044 \\
CB12009 & 491.763 & 0.077 & 1.212741 & 0.000039 & 491.756 & -0.007 \\
\hline
\end{tabular}

Table 5. Results of mother-daughter testing on $29.5 \mathrm{~L}$ aluminum cylinders. Note that final pressures do not sum correctly due to thermal differences. Mother-daughter differences were calculated as daughter minus mother (after transfer).

\begin{tabular}{llrlr}
\hline Cylinder & \multicolumn{3}{c}{$\sim$} & $\mathrm{CO}_{2}(\mathrm{ppm})$ \\
\hline $\mathrm{CB} 11795$ & Mother & 12.07 & initial & 401.928 \\
$\mathrm{CB} 11795$ & Mother & 5.79 & after transfer & 401.988 \\
$\mathrm{CB} 11941$ & Daughter & 0.03 & initial & $\mathrm{n} / \mathrm{a}$ \\
$\mathrm{CB} 11941$ & Daughter & 5.72 & after transfer & 401.828 \\
& & & change in mother & 0.06 \\
& & & daughter-mother & -0.16 \\
\hline CB11088 & Mother & 13.80 & initial & 408.125 \\
CB11088 & Mother & 6.69 & after transfer & 408.188 \\
CB11873 & Daughter & 0.03 & initial & $\mathrm{n} / \mathrm{a}$ \\
$\mathrm{CB} 11873$ & Daughter & 6.55 & final & 407.995 \\
& & & change in mother & 0.06 \\
& & & daughter-mother & -0.19 \\
\hline
\end{tabular}

n/a: not applicable

this level of agreement could be achieved with poor or variable transfer efficiency.

As mentioned earlier, we estimated the amount of $\mathrm{CO}_{2}$ adsorbed to the cylinder walls $(\sim 0.004 \%)$ from the results of low-flow decanting experiments. The Schibig et al. (2018) decanting tests reveal substantially less $\mathrm{CO}_{2}$ adsorbed compared to "mother-daughter" tests (Miller et al., 2015; Brewer et al., 2018), in which half the contents of one cylinder are transferred to an equal size cylinder and the adsorption determined based on the resulting mole fraction difference. From mother-daughter tests on 5.9 L cylinders from Airgas (Riverton, $\mathrm{NJ}$ ) and $5 \mathrm{~L}$ cylinders from Air Products (Vilvoorde, Belgium), Miller et al. (2015) estimated that about $0.02 \%$ of the $\mathrm{CO}_{2}$ was adsorbed to the walls. Brewer et al. (2018) performed similar tests on $10 \mathrm{~L}$ aluminum cylinders treated with the BOC Spectra Seal process and found $\mathrm{CO}_{2}$ adsorption fractions of about $0.05 \%$.

In preparation for this work, we performed motherdaughter tests on both 5.9 and $29.5 \mathrm{~L}$ aluminum cylinders (Scott Marrin, Riverside, CA), including cylinders CB11941 and CB11873 used in this work. Cylinders CB11941 and CB11873 were filled with natural air, vented, and then evacuated to 5 psia $(0.03 \mathrm{MPa})$. Air from two mother cylinders containing natural air was transferred into CB11941 and $\mathrm{CB} 11873$. We found that the $\mathrm{CO}_{2}$ in daughter cylinders CB11941 and CB11873 was 0.16-0.19 ppm lower than their respective mothers after transfer (Table 5), similar to the results of Miller et al. (2015) and Brewer et al. (2018). Our tests with $5.9 \mathrm{~L}$ cylinders also showed differences of $\sim 0.2 \mathrm{ppm}$ (not shown).

Mother-daughter tests suggest 5 to 10 times more adsorption than that determined from the Schibig et al. (2018) low-flow data. The difference between mother-daughter tests and the low-flow experiments could be related to thermal fractionation. Schibig et al. (2018) performed both lowflow $\left(0.3 \mathrm{~L} \mathrm{~min}^{-1}\right)$ and high-flow $\left(5.0 \mathrm{~L} \mathrm{~min}^{-1}\right)$ decanting experiments. They found that changes in $\mathrm{CO}_{2}$ at the high flow rate were 2.5 times those observed at the low flow rate and attributed the difference to thermal fractionation at the higher flow rate. During our mother-daughter tests, the mother cylinders experienced significant cooling during transfer, which could have caused fractionation as cooler air sinks in the center core of the cylinder, with $\mathrm{CO}_{2}$ preferentially remaining in the mother cylinder. In fact, after transferring half of the gas from a mother cylinder to a respective daughter cylinder, the mole fraction of $\mathrm{CO}_{2}$ in each mother 
cylinder increased $0.06 \pm 0.01 \mathrm{ppm}$ relative to its value determined prior to transfer (Table 5). From Fig. 2, which represents a typical low-flow decanting result, the increase due to desorption from the cylinder walls should be far smaller than $0.06 \mathrm{ppm}$ at $50 \%$ of the original cylinder pressure.

Finally, we compare these standards to the WMO X2007 $\mathrm{CO}_{2}$ scale. The mean ratio of gravimetrically assigned mole fractions to values assigned on the WMO X2007 scale is 1.00045 with a standard deviation of 0.00017 . Thus, the WMO X2007 scale is $\sim 0.05 \%$ lower than a scale based on these gravimetric standards. However, this difference is not outside the range of uncertainties $(\sim 0.05 \%$ for WMO X2007 and $\sim 0.033 \%$ for this work, $\sim 95 \%$ confidence level, or coverage factor $k=2$ ). While the ${ }^{13} \mathrm{C}-\mathrm{CO}_{2}$ content of these gravimetrically prepared standards is lower than that of natural air $(-29 \%$, compared to about $-8 \%$ o for natural air), and these standards were compared to WMO secondary standards with ${ }^{13} \mathrm{C}-\mathrm{CO}_{2}$ at ambient levels during analysis, this introduces negligible bias because the analytical method compensates for different isotopic abundances (Tans et al., 2017). Further discussion on differences between the WMO X2007 scale and these gravimetric standards will be included in a subsequent publication.

\section{Conclusions}

Five gravimetric $\mathrm{CO}_{2}$-in-air standards, prepared at the parts per million level in one dilution step, show excellent internal consistency. Prepared mole fractions were adjusted for $\mathrm{CO}_{2}$ expected to adsorb to cylinder walls. This correction was determined from low-flow decanting studies and is a factor of 5-10 smaller than that inferred from mother-daughter tests. With improved understanding of $\mathrm{CO}_{2}$ adsorption characteristics, and by introducing condensed-phase aliquots of $\mathrm{CO}_{2}$ into small vessels that can be weighed with sufficient repeatability, $\mathrm{CO}_{2}$-in-air standards can be prepared with relatively low uncertainty. This work supports parallel efforts to maintain the WMO mole fraction scale for $\mathrm{CO}_{2}$.

Data availability. Most relevant data are included in Tables 1-3. Data needed to calculate values in Table 3 are available in Schibig et al. (2018). Additional data are available in the Supplement.

Supplement. The supplement related to this article is available online at: https://doi.org/10.5194/amt-12-517-2019-supplement.

Author contributions. BDH designed the experiment, carried out the laboratory work, and prepared the standards. AMC and BJM performed purity analysis. MS performed cylinder stability tests. $\mathrm{BDH}$ prepared the paper with contributions from all authors.
Competing interests. The authors declare that they have no conflict of interest.

Acknowledgements. This work was supported, in part, by NOAA's Atmospheric Chemistry, Carbon Cycle, and Climate program (AC4). Michael Schibig was supported by an Early Postdoc Mobility fellowship from the Swiss National Science Foundation (SNSF) while working at NOAA in Boulder, CO. The authors thank Thomas Mefford for performing the analysis and Duane Kitzis for providing cylinders of clean, unpolluted air.

Edited by: Marc von Hobe

Reviewed by: three anonymous referees

\section{References}

Brewer, P. J., Brown, R. J. C., Miller, M. N., Miñarro, M. D., Murugan, A., Milton, M. J. T., and Rhoderick, G. C.: Preparation and Validation of Fully Synthetic Standard Gas Mixtures with Atmospheric Isotopic Composition for Global $\mathrm{CO} 2$ and CH4 Monitoring, Anal. Chem., 86, 1887-1893, https://doi.org/10.1021/ac403982m, 2014.

Brewer, P. J., Brown, R. J. C., Resner, K. V., Hill-Pearce, R. E., Worton, D. R., Allen, N. D. C., Blakley, K. C., Benucci, D., and Ellison, M. R.: Influence of Pressure on the Composition of Gaseous Reference Materials, Anal. Chem., 90, 3490-3495, https://doi.org/10.1021/acs.analchem.7b05309, 2018.

Dlugokencky, E. J., Myers, R. C., Lang, P. M., Masarie, K. A., Crotwell, A. M., Thoning, K. W., Hall, B. D., Elkins, J. W., and Steele, L. P.: Conversion of NOAA atmospheric dry air $\mathrm{CH}_{4}$ mole fractions to a gravimetrically prepared standard scale, J. Geophys. Res.-Atmos., 110, https://doi.org/10.1029/2005JD006035, 2005.

Keeling, C. D., Guenther, P. R., and Moss, D. J.: Scripps reference gas calibration system for carbon dioxide-in-air standards: revision of 1985, Gaw Report No. 42, WMO, Geneva, Switzerland, 1986.

Keeling, C. D., Guenther, P. R., Emanuele, G., Bollenbacher, A., and Moss, D. J.: Scripps reference gas calibration system for carbon dioxide-in-nitrogen and carbon dioxide-in-air standards: revision of 1999, Scripps Institution of Oceanography, La Jolla, CA, 2002.

Langenfelds, R. L., van der Schoot, M. V., Francey, R. J., Steele, L. P., Schmidt, M., and Mukai, H.: Modification of air standard composition by diffusive and surface processes, J. Geophys. Res.-Atmos., 110, https://doi.org/10.1029/2004JD005482, 2005.

Leuenberger, M. C., Schibig, M. F., and Nyfeler, P.: Gas adsorption and desorption effects on cylinders and their importance for long-term gas records, Atmos. Meas. Tech., 8, 5289-5299, https://doi.org/10.5194/amt-8-5289-2015, 2015.

Machida, T., Tohjima, Y., Katsumata, K., and Mukai, H.: A new $\mathrm{CO}_{2}$ calibration scale based on gravimetric one-step dilution cylinders in National Institute for Environmental Studies - NIES $09 \mathrm{CO}_{2}$ Scale, Gaw Report No. 194, WMO, Geneva, Switzerland, 165-169, 2011.

Miller, W. R., Rhoderick, G. C., and Guenther, F. R.: Investigating Adsorption/Desorption of Carbon Dioxide in Alu- 
minum Compressed Gas Cylinders, Anal. Chem., 87, 19571962, https://doi.org/10.1021/ac504351b, 2015.

Rhoderick, G. C., Kitzis, D. R., Kelley, M. E., Miller, W. R., Hall, B. D., Dlugokencky, E. J., Tans, P. P., Possolo, A., and Carney, J.: Development of a Northern Continental Air Standard Reference Material, Anal. Chem., 88, 3376-3385, https://doi.org/10.1021/acs.analchem.6b00123, 2016.

Schibig, M. F., Kitzis, D., and Tans, P. P.: Experiments with $\mathrm{CO}_{2}-$ in-air reference gases in high-pressure aluminum cylinders, Atmos. Meas. Tech., 11, 5565-5586, https://doi.org/10.5194/amt11-5565-2018, 2018.

Sutour, C., Stumpf, C., Kosinski, J. P., Surget, A., Hervouët, G., Yardin, C., Madec, T., and Gosset, A.: Determination of the argon concentration in ambient dry air for the calculation of air density, Metrologia, 44, 448-452, 2007.

Tans, P. P., Crotwell, A. M., and Thoning, K. W.: Abundances of isotopologues and calibration of $\mathrm{CO}_{2}$ greenhouse gas measurements, Atmos. Meas. Tech., 10, 2669-2685, https://doi.org/10.5194/amt-10-2669-2017, 2017.
Trolier, M., White, J. W. C., Tans, P. P., Masarie, K. A., and Gemery, P. A.: Monitoring the isotopic composition of atmospheric $\mathrm{CO}_{2}$ : Measurements from the NOAA Global Air Sampling Network, J. Geophys. Res.-Atmos., 101, 25897-25916, https://doi.org/10.1029/96JD02363, 1996.

WMO: 19th WMO/IAEA Meeting on Carbon Dioxide, Other Greenhouse Gases and Related Tracers Measurement Techniques (GGMT-2017), Geneva, Switzerland, 2018.

Zhao, C. L., Tans, P. P., and Thoning, K. W.: A high precisionmanometric systemfor absolutecalibrations of $\mathrm{CO}_{2}$ in dry air, J. Geophys. Res., 102, 5885-5894, 1997.

Zhao, C. L. and Tans, P. P.: Estimating uncertainty of the WMO mole fraction scale for carbon dioxide in air, J. Geophys. Res., 111, https://doi.org/10.1029/2005JD006003, 2006. 